\title{
JÚPITER, HÉRCULES, HERMES: TRES MODELOS DE JUEZ
}

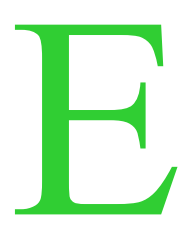

n el número de junio de 1990 de la Revue de l'Ecole nationale de la magistrature se describe en estos términos la profesión de magistrado: «No existe de manera evidente ningún otro modelo de referencia, ninguna otra definición unívoca de una profesión que tienda a volverse tan multiforme y pluralista». La constatación, a su vez, se inscribe en la observación de un campo judicial y jurídico definido como «heterogéneo y complejo», de tal manera que las evoluciones en curso impiden «toda referencia a la idea de un modelo» ${ }^{1}$.

Paradójicamente, esta crisis de los modelos proviene, sin duda, no tanto de la ausencia de referencias como de su excesiva abundancia; como si el jurista, y particularmente el juez, no llegase a elegir, en el surtido de los accesorios de la justicia, el uniforme que convenga a los roles múltiples que en lo sucesivo se esperan de él. ¿Será la toga, el falso cuello o la blusa, por retomar el catálogo propuesto en su tiempo por André-Jean Arnaud ${ }^{2}$ ? Esta manera de proliferación -a la que no es extraña cierto sentimiento de burla engendrado por la conciencia misma de disfraz- podría ser, calificándola de entrada, uno de los rasgos del postmodernismo, caracterizado precisamente por la superposición y las interferencias constantes de los juegos del lenguaje.

¿Cómo construir entonces el modelo de quien parece sustraerse a la modelización? Podríamos, quizá, comenzar evocando dos figuras

${ }^{1}$ Revue de l'Ecole nationale de la magistrature, n. ${ }^{\circ}$ 3, junio, 1990, págs. 14-15.

${ }^{2}$ A.-J. Arnaud, «Le Mediumet le savant. Signification politique de l'interpretationjuridique», en Archives de philosophie du droit, 1972, págs. 172 y ss.; y también F. Ost, «Juge pacificateur, juge arbitre, juge entraîneur. Trois modèles de justice, en Fonction de juger et pouvoir judiciare. Transformations et déplacements, bajo la dirección de Ph. Gérard, F. Ost y M. van Kerchove, Bruselas, 1983, págs. 1-70. 
extremas de la juridicidad, para trazar inmediatamente, en el vacío que los separa o la saturación que a veces los aproxima, la vía de una tercera figura que, por su misma complejidad, podría responder a la presente diseminación de las teorías, valores y discursos.

Tomemos el modelo de la pirámide o del código. Lo llamaremos el Derecho jupiterino. Siempre proferido desde arriba, de algún Sinaí, este Derecho adopta la forma de ley. Se expresa en el imperativo y da preferencia a la naturaleza de lo prohibido. Intenta inscribirse en un depósito sagrado, tablas de la ley o códigos y constituciones modernas. De ese foco supremo de juridicidad emana el resto del Derecho en forma de decisiones particulares. Se dibuja una pirámide, impresionante monumento que atrae irresistiblemente la mirada hacia arriba, hacia ese punto focal de donde irradia toda justicia. Evidentemente ese Derecho jupiterino está marcado por lo sagrado y la trascendencia.

De este modo la aparición del segundo modelo, el modelo herculeano que nos trae sobre la tierra, toma la figura de revolución -gesto iconoclasta que hace del hombre, más concretamente del juez, la fuente del único Derecho válido-. En la huella de las diversas corrientes que se declaran realistas -pensamos especialmente en el «realismo americano» y particularmente en la sociological jurisprudence-, entra en juego un modelo que calificaría de embudo (pirámide invertida) o de dossier. Es Ronald Dworkin, como es sabido, quien, revalorizando hasta el extremo la figura del juez moderno, le da los rasgos de Hércules. Sin poder -lejos de pretenderlo- reducir la posición de Dworkin a la de los realistas americanos, mantendremos aquí el nombre de Hércules, particularmente acertado para designar a ese juez semidiós que se somete a los trabajos agotadores de juzgar y acaba por llevar el mundo sobre sus brazos extendidos, reproduciendo así fielmente la imagen del embudo. A partir de aquí no hay más Derecho que el jurisprudencial; es la decisión y no la ley la que crea autoridad. Al código lo sustituye el dossier; la singularidad y lo concreto del caso se superponen a la generalidad y abstracción de la ley. Este cambio de perspectiva nos lleva desde las cimas de la trascendencia de la ley hacia la inmanencia de nuestros intereses en conflicto. La pirámide sugería lo sagrado y lo ideal; el embudo evoca la materia, lo profano, incluso lo alimenticio. Al predominio de una justicia inspirada por el mandato jupiterino, le sustituye la balanza de nuestros cálculos y compensaciones cotidianas.

Podríamos, evidentemente, quedarnos ahí y comentar cómodamente el entrelazamiento de estas dos figuras. No sería muy difícil mostrar cómo el modelo de la pirámide traduce las exigencias del Estado liberal o Estado de Derecho del siglo XIX y el modelo del embudo, las actividades del Estado social o asistencial del siglo XX. 
Sería fácil concluir a continuación que nuestra actualidad jurídica se caracteriza por una combinación, variable según las ramas del Derecho, de las dos racionalidades jurídicas que acabamos de distinguir sumariamente. De la primera habríamos heredado, junto a los códigos y las constituciones, los principios y los conceptos que estructuran nuestra disciplina; mientras que la segunda nos proporcionaría esos jueces que, desde la justicia constitucional hasta la justicia de los procedimientos de urgencia, parecen ejercer ahora el monopolio de la jurisdictio.

Sin embargo, esto supondría salir del paso sin demasiado esfuerzo, dejando de lado lo esencial. Todo lleva a creer, en efecto, que la complejidad que se nos presenta es todavía mucho más grande que la sugerida por la superposición de estos dos modelos. Además del hecho de que uno y otro han entrado hoy en crisis, ellos sólo ofrecen representaciones empobrecidas de la situación que pretendían describir en su época. La sociedad y el Derecho postmodemo merecen algo mejor que ese artificio teórico. Nos encontramos entonces ante la configuración de un nuevo modelo en el que conviene fijarse.

Proponemos representar este modelo bajo los rasgos de Hermes, el mensajero de los dioses $^{3}$. Siempre en movimiento, Hermes está a la vez en el cielo, sobre la tierra y en los infiernos. Ocupa resueltamente el vacío entre las cosas, asegura el tránsito de unas a otras. Dios de los mercaderes, preside los intercambios; psicopompo, conecta los vivos y los muertos; dios de los navegantes, supera travesías desconocidas. Hermes es el mediador universal, el gran comunicador. No conoce otra ley que la circulación de los discursos, con la que arbitra los juegos siempre recomenzados.

${ }^{3}$ La figura de Hermes no es desconocida en el pensamiento jurídico. Algunos autores la evocan, aunque con sentidos muy diferentes de los que nos ocuparemos. L. Sala-Molins ( La Loi, de quel droit? París, 1977, págs. 29 y ss., y págs. 103 y ss.) lo presenta como el heraldo de la ley universal del deseo, que se aprovecha de la ley política. El autor le atribuye la filosofía de Ramón Llull, con la que está de acuerdo, y que podría expresarse en estas palabras: «Yo me basto, al diablo la ley»». Esta aproximación a Hermes nos parece totalmente restrictiva; lejos de ser la expresión de una voz solipsista, Hermes es al contrario el intérprete, el mediador, el portavoz. Según Sala Molins, ningún lugar es reservado al diálogo y a la mediación; ya que la palabra no era más que monólogo, afirmación del yo, la ley no será más que violencia, y el juicio, inquisición. Otro autor contemporáneo evoca igualmente a Hermes: R. Dworkin (Law's empire, London, 1986, págs. 317 y ss.), quien lo traza esta vez bajo los rasgos del juez que interpreta la ley en función de la voluntad del legislador, método que critica el autor, particularmente por la imposibilidad de identificar tal voluntad. Varios rasgos diferencian nuestro Hermes del de Dworkin: 1.-Para Dworkin, se trata exclusivamente de un juez, mientras que, para nosotros, Hermes representa todo actor jurídico, todo locutor que se expresa en el discurso jurídico, aunque sea un simple particular, a condición de que adopte la actitud «hermenéutica» 
Si la montaña o la pirámide convenían a la majestad de Júpiter, y el embudo al pragmatismo de Hércules, en cambio, la trayectoria que dibuja Hermes adopta la forma de una red. No tanto un polo ni dos, ni incluso la superposición de los dos, sino una multitud de puntos en interrelación. Un campo jurídico que se analiza como una combinación infinita de poderes, tan pronto separados como confundidos, a menudo intercambiables; una multiplicación de los actores, una diversificación de los roles, una inversión de las réplicas. Tal circulación de significados e informaciones no se deja ya contener en un código o en un dossier; se expresa bajo la forma de un banco de datos. El Derecho postmodemo, o Derecho de Hermes, es una estructura en red que se traduce en infinitas informaciones disponibles instantáneamente y, al mismo tiempo, difícilmente matizables, tal como puede serlo un banco de datos. Sin embargo, para intentar describir estos juegos del lenguaje infinitamente complejos y enredados, propondremos algunos aspectos de lo que se podrá llamar una teoría lúdica del Derecho. Finalmente, terminaremos dejando en toda su radicalidad la cuestión de la legitimidad: pues si Hermes no es ni trascendencia ni inmanencia, sino, una vez más, se encuentra entre la una y la otra (dialéctica) o, mejor todavía, paradoja (la una y la otra), entonces tendremos que, igualmente, aprender a reformular nuestras respuestas a la cuestión del «buen Derecho».

Pero antes de seguir con Hermes en las redes laberínticas del Derecho postmoderno, debemos profundizar un poco en el modelo de la pirámide y en el del embudo.

\section{Júpiter, la pirámide y el código}

El modelo jurídico clásico, que continúa siendo enseñado en las facultades de Derecho y que mantiene las representaciones canónicas de los juristas, modelo que además conserva alguna forma de aplicación práctica, es el modelo del Derecho codificado. La inspiración de tal Derecho está generalmente ligada a un autor único y supremo: Licurgo, Solón, Justiniano o Napoleón. Jean-Jacques

que representamos como la propia del «modelo de Hermes». 2.-Para Dworkin, el juez Hermes se consagra a interpretar la ley en el sentido correspondiente a la voluntad del legislador, mientras que, para nuestro jurista Hermes, la voluntad del autor del texto sólo representa un elemento entre otros que concurren a determinar el sentido óptimo de las normas a interpretar. En definitiva, el juez Hermes de Dworkin privilegia la voluntad del legislador, mientras que nuestro jurista Hermes se esfuerza por integrar, en la construcción del sentido jurídico, las creaciones normativas que emanan de otras fuentes como la jurisprudencia, las costumbres, las convenciones internacionales, los principios generales del Derecho, la doctrina, etc. 
Rousseau, gran teórico de la religión civil, bosqueja el retrato de ese codificador fuera de lo común: «Para descubrir las mejores reglas de la sociedad que convienen a las naciones -escribe en el Contrato Social- haría falta una inteligencia superior que viera todas las pasiones de los hombres, que no tuviera ninguna relación con nuestra naturaleza y la conociera a fondo, cuya suerte fuera independiente de nosotros $\mathrm{y}$, por tanto, quisiera ocuparse bien de lo nuestro, que en el progreso de los tiempos se procurara una gloria lejana, pudiera trabajar en un siglo y gozar en otro. Harían falta dioses para dar leyes a los hombresı ${ }^{4}$.

Tal Derecho codificado, reducido a la simplicidad de una obra única, se articula en forma jerárquica y piramidal. Los teóricos modernos y positivistas del Derecho, como Merkl y Kelsen, que se creían libres de toda mitología, proponen la teoría bajo la forma de «construcción del Derecho por gradas» (Stufenbau). Según Kelsen, un sistema jurídico «no es un complejo de normas en vigor, unas junto a otras, sino una pirámide o jerarquía de normas que son superpuestas o subordinadas las unas a las otras, superiores o inferiores» ${ }^{5}$. A una cascada de poderes, rigurosamente subordinados los unos a los otros, responde un escalonamiento de reglas jerárquicamente derivadas. El movimiento que anima esta construcción es siempre lineal y unidireccional: si se trata de apreciar el fundamento de validez de las normas, se ascenderá de la norma inferior a la norma superior para llegar a la norma fundamental que habilita a la autoridad suprema a crear Derecho válido; si se trata, en cambio, de prever la creación de una nueva norma jurídica, se tomará el camino inverso, partiendo de esta primera habilitación para recorrer seguidamente los siguientes escalones de la jerarquía normativa. Cada norma se analiza a la vez como aplicación o individualización de la norma superior y habilitación para el órgano creador de la norma inferior.

La ordenación lógica de esta construcción enmascara bastante mal, en nuestra opinión, la teología política implícita que la inspira. En este punto, W. Krawietz ha podido mostrar que la soberanía del legislador (princeps legibes solutus) no sería más que la laicización de la suprema potestas divina, mientras que la articulación de las normas jurídicas positivas transpondría la cascada normativa que, especialmente, santo Tomás establece entre lex divina, lex aeterna,

${ }^{4}$ J.-J. Rousseau, Du contrat social. Des principes du droit politique. París, 1972, pág. 107.

${ }^{5}$ H. Kelsen, Théorie pure du droit, 2. ${ }^{a}$ ed., trad. por Ch. Eisenmann, París, 1962. pág.255. 
lex naturalis y lex positiva ${ }^{6}$ Por lo demás, el mismo Kelsen, que jamás ha cesado de reconsiderar el estatus de la norma fundamental, terminará por admitir que una norma debe necesariamente expresar el significado de un acto de voluntad y no sólo de una hipótesis intelectual. Suponer la norma fundamental significa suponer igualmente la existencia de una «autoridad imaginaria» que «quiere» esa norma. Esto es, sin duda, una ficción, pero una ficción necesaria para la validación positivista de los órdenes jurídicos en vigor ${ }^{7}$. Si se quiere asegurar la unidad y la validez de un sistema jurídico, se hará «como si» algún ser imaginario le hubiera dado el impulso inicial. Júpiter ya no está, decididamente, muy lejano.

La racionalización última de este modelo jurídico (fenómeno que -como ha recordado Max Weber- se extiende durante siglos) llega a las constituciones modernas. Se impone la idea de reunir todo el material jurídico en un Codex unitario que presente las cualidades de coherencia, completitud, claridad, no redundancia, simplicidad y manejabilidad. No sólo simple yuxtaposición o compilación de soluciones casuísticas, sino también verdadera transubstanciación de las reglas por el efecto de la sistematización de sus conceptos y de sus principios estrictamente derivados de algunos axiomas iniciales.

El logro de las codificaciones no pasa sólo por cierta racionalización formal; implica también una simplificación radical del material jurídico concomitante para una nivelación del propio sistema social. Haciendo tabla rasa del pasado, inspirado en una nueva concepción de lo social, el codificador reescribe el Derecho restableciendo algunas categorías esenciales. Una coincidencia destacable se observa así entre las codificaciones conseguidas y el reforzamiento del poder político; se trata del triunfo de una forma de despotismo ilustrado, de un fenómeno de liberación nacional o del resultado de un proceso revolucionario.

En nuestra opinión, el modelo del código conlleva, en definitiva, cuatro corolarios.

El primero es el del monismo jurídico. Por oposición a la dispersión de los focos del Derecho, el material jurídico adopta en lo sucesivo

${ }^{6}$ W. Krawietz, «Die Lehre vom Stufenbau des Rechts. Eine säkularisierte politische Theologie? en Rechstheorie, vol. 5, Berlín, págs. 257-261.

${ }^{7}$ H. Kelsen, «Die Funktion der Verfassung» en Die Wiener Rechtsheoretische Schule Schriften von Hans Kelsen, Adolf Merkl, Alfred Verdross, ed. H. Klecatsky, R. Marcie y H. Schambeck, t. I, Viena, 1968, pág. 1977. Sobre esta cuestión, cf. F. Ost y M. van de Kerchove, «La Référence à Dieu dans la théorie pure du droit de Hans Kelsen», en Qu'est-ce que Dieu? Hommage à l'abbé Daniel Coppieters de Gibson, Bruselas, 1985, págs. 285-324. 
la forma dominante de la ley y ésta se acopla en códigos, reforzando aún más la sistematicidad y la autoridad.

El segundo corolario es el del monismo político o de la soberanía estatal. La codificación -del mismo modo que el establecimiento de la Constitución en la cúspide de la pirámide normativa- supone el resultado de un proceso de identificación nacional y de centralización administrativa que culmina en la figura del soberano. A la multiplicidad de instituciones, estados y cuerpos intermediarios del Antiguo Régimen le sustituye ahora el espacio míticamente unificado de la voluntad nacional. A los múltiples consensos sectoriales y locales los sustituye el consenso nacional -real o impuesto, poco importa aquí- cuyo código traduce las principales opciones.

El tercer corolario inherente a la idea de codificación es el de una racionalidad deductiva y lineal: las soluciones particulares son deducidas de reglas generales, derivadas ellas mismas de principios todavía más generales siguiendo inferencias lineales y jerarquizadas. El argumento fuerte de la controversia jurídica no es otro que la invocación, en apoyo de la interpretación que se sostiene, de la racionalidad del legislador, garante jupiterino de la coherencia lógica y de la armonía ideológica del sistema.

Por último, la codificación supone además una concepción del tiempo orientado hacia un futuro controlado. Por oposición al tiempo de larga duración (temporalidad que sobre todo mira hacia el pasado y caracteriza al Derecho consuetudinario), la empresa de la codificación descansa sobre la creencia, eminentemente moderna, del progreso de la historia: la idea de que la ley -anticipando un estado de cosas posible y considerado preferible- puede hacer llegar un porvenir mejor ${ }^{8}$.

En resumen, como recuerda Pierre Bourdieu, «la codificación pone las cosas simples, claras, comunicables» ${ }^{9}$. Sin embargo, si es verdad que hemos entrado resueltamente en la era de la complejidad, puede sospecharse que el paradigma de la pirámide y del código ha entrado en una profunda crisis. Hay que extrañarse en estas condiciones de que algunos, deseosos de desprenderse radicalmente de este primer modelo, sigan la vía de la inversión completa -vía de la revolución, de la que por tanto habría que pensar que significa también «vuelta al punto de partida»-. Siguiendo entonces la «ley de la bipolaridad de los errores», de la cual hablaba Gaston Bachelard,

${ }^{8}$ Sobre esto cf. F. Ost, «Codifier en 1987?», en Journal des Procés, n. ${ }^{\circ} 116$, noviembre 1987, págs. 16 y ss.

${ }^{9}$ Bourdieu, «Habitus, code et codification», en Actes de la recherche en sciences sociales, n. ${ }^{\circ} 64$, septiembre 1986, pág. 42. 
consistente en no abandonar una posición errónea, sino para ocupar inmediatamente la posición opuesta, que es igualmente reduccionista y comparte sin duda con la primera un cierto número de rasgos esenciales ${ }^{10}$, ciertos autores van a hacer del juez, de cada juez, el foco exclusivo de la juridicidad.

\section{Hércules, el embudo y el dossier}

Hay algo trágico en la figura de Hércules, como también en la de Prometeo, que no es ajeno a aquél (¿no se dice que es Hércules precisamente quien libera a Prometeo del peñón caucásico, al que estaba encadenado por haber robado el fuego de los dioses para regalárselo a los hombres?). Hércules, como es bien sabido, es castigado con la maldición de Hera; él no deja de expiar el infanticidio que ella le ha incitado a cometer. Su actividad desbordante determina el perdón de esta falta. ¿Qué falta expía entonces nuestro herculeano juez moderno? ¿La dureza del liberalismo económico que se desarrolló al amparo del «juridicismo» formal? ¿La miopía legalista de la exégesis del siglo XIX?

Nunca nada será perdonado al «juez-asistencial» de hoy. Conciliar las economías familiares en crisis; dirigir las empresas en dificultades evitando, si es posible, la quiebra; juzgar si corresponde al interés del niño ser reconocido por su padre natural, si la madre se opone (art. 319.3 del Código civil belga); apreciar si la interrupción voluntaria del embarazo se justifica por el «estado de angustia» de la mujer embarazada (art. 348 y ss. del Código penal belga); intervenir «en caliente» en los conflictos colectivos de trabajo y decidir (en procedimiento de extrema urgencia un catorce de agosto a medianoche) si la huelga de los pilotos aéreos de la compañía nacional, prevista para el día siguiente a las seis, es o no lícita $^{11}$; juzgar si un aumento de capital decidido con el objeto de oponerse a una oferta pública de compra de un holding, cuya cartera representa un tercio de la economía belga, es conforme a la ley ${ }^{12}$; imponer moratorias a los trabajadores o a las empresas que amenazan el equilibrio ecológico;

${ }^{10}$ Sobre este punto, cf. F. Ost y M. van de Kerchove, «De la 'bipolarité des erreurs', ou de quelques paradigmes de la science du droit», en Archives de philosophie du droit, París, Sirey, t. 33, 1988, págs. 177 y ss.

${ }^{11}$ Trib. civ. Bruxelles (réf.), 15 de agosto de 1987, inédito; acerca de toda la cuestión cf. F. Ost, «Rapport général de synthèse», en Les conflits collectifs en droit du travail. Solutions négociées ou interventions judiciaires?, bajo la dirección de J. Guillardin y P. Van Der Vorst, Bruxelles, 1989, págs. 109-131.

${ }^{12}$ Trib. comm. Bruxelles (réf.), en Journal des Procés, 1988. 
juzgar si llevar el velo islámico es compatible con la disciplina y el espíritu de la escuela... Hércules está presente en todos los frentes, decide e incluso aplica normas como lo hacía su predecesor, que se amparaba en la sombra del código; pero también lleva a cabo otros trabajos. En el precontencioso aconseja, orienta, previene; en el postcontencioso sigue la evolución del dossier, adapta sus decisiones al grado de circunstancias y necesidades, controla la aplicación de las penas. El juez jupiterino era un hombre de ley; respecto a él, Hércules se desdobla en ingeniero social.

Se comprende que tal evolución, sobre todo en lo que afecta a las jurisdicciones constitucionales habilitadas para apreciar la constitucionalidad de las leyes (o que progresivamente se van atribuyendo estas competencias, como la Corte Suprema de los Estados Unidos), conduce a relativizar el mito de la supremacía del legislador. Es precisamente en los Estados Unidos, con las corrientes del realismo y de la sociological jurisprudence, donde esta puesta en cuestión encontrará su expresión más radical.

Es el juez O. W. Holmes quien primero hace tambalear la relación jerárquica tradicional entre reglas y decisiones, creación y aplicación del Derecho, definiendo lo jurídico en estos términos: «Las profecías de lo que harán efectivamente los jueces y los tribunales, y nada más pretencioso, eso es lo que yo entiendo por 'Derecho' $\gg^{13}$. Desde esta perspectiva, el Derecho no es tanto un deber-ser, un conjunto de reglas, sino un fenómeno fáctico complejo formado por los comportamientos de las autoridades judiciales. Se opera así un cambio radical de perspectiva que representa desde ahora el Derecho en forma de pirámide invertida o de embudo. J. Frank ha calificado oportunamente este cambio de paradigma de «revolución copernicana»: mientras que el pensamiento jurídico tradicional coloca las reglas en el centro del sistema y cree poder deducir mecánicamente las decisiones particulares, Holmes y el movimiento realista colocan las decisiones judiciales en el corazón del sistema ${ }^{14}$. Las reglas generales y normativas son configuradas con el rango de paper rules (Llewellyn), simples posibilidades jurídicas, correspondiendo a los jueces darles consistencia en sus decisiones particulares -real rules-, formuladas en indicativo.

El punto de vista clásico, impregnado de moralismo, que privilegia la regla y el deber de obediencia, se sustituye ahora por el punto

${ }^{13}$ O. W. Holmes, The path of the law (1987), reproducido en The Bobbs-Merril law reprint series, pág. 461 .

${ }^{14}$ J. Frank, Mr Justice Holmes and non-euclidean legal thinking (1932), reproducido en Readings in jurisprudence, Indianápolis, 1938, pág. 368. 
de vista del bad man, que se preocupa exclusivamente de las eventuales consecuencias desagradables de sus actos. La cuestión no es ya: «¿cuál es mi deber?», sino «¿qué probabilidad hay de que una jurisdicción sancione mi comportamiento? ${ }^{15}$. Se entiende que, a partir del momento en el que la regla no constituye más que una justificación de la decisión (en la medida en que ella no se impone a priori al decisor), aquélla sólo representará una predicción de la futura decisión. No es tanto la decisión la que deriva de la regla, sino ésta de aquélla.

Sin duda, tal modelo es muy diferente del anterior; se puede pensar sin embargo que reproduce, por un efecto de espejo, la imagen inversa. Se trata, por una parte, de la incapacidad de los dos paradigmas para articular, de manera satisfactoria, el hecho y el Derecho y, por otra parte, -y esto no es ajeno a aquello- de una forma de obliteración de la vida jurídica real; el Derecho se disuelve, en última instancia, en los lugares imaginarios de los que se considera procedente: vértice de la pirámide o extremidad del embudo.

Tomemos el Derecho herculeano. Aquí la efectividad (la irrecusabilidad del hecho) es condición necesaria y suficiente para la validez; la legalidad de la regla y, a fortiori, su legitimidad no se toman en consideración. El Derecho se reduce al hecho, a la indiscutible materialidad de la decisión. Pero entonces es la idea misma de validez y, con ella, la de normatividad la que pierde pertinencia. ¿No reconocen los mismos realistas que sus real rules se conjugan en indicativo? Se asiste aquí no solamente a una atomización de lo jurídico, disperso en una multitud de decisiones, sino también, y fundamentalmente, a una disolución de lo normativo que se agota en una colección dispersa de manifestaciones esporádicas de voluntad. La decisión, en estas condiciones, ya no recoge nada de lo normativo de la regla (por definición ausente) y se analiza desde ahora como «el hecho del juez» que ninguna regularidad normativa quiere validar. Como bien lo ha entendido un representante de esta corriente, J. Brawn, el Derecho, en definitiva, no existe en ninguna parte: no está ni en la ley ni en las decisiones judiciales, pasadas o incluso presentes (salvo, en lo que concierne a estas últimas, para las partes en litigio). No es nunca otra cosa que devenir; su único lugar de emergencia es la decisión singular, pero en cuanto aparece, expira $^{16}$.

Tomemos el Derecho jupiternino. Aquí es la legalidad la que es condición necesaria y suficiente para la validez de la regla. Es suficiente, para una norma, haber sido dictada por la autoridad competente

${ }^{15}$ O.W. Holmes, op. cit., pág. 459.

${ }^{16}$ J. Brown, «Law and evolution», en Yale law Journal, 1929, pág. 394. 
y según los procedimientos; las cuestiones anteriores de legitimidad y ulteriores de efectividad no son pertinentes a este respecto. Todavía aquí es defectuosa la vía jurídica real, que es articulación del hecho y del Derecho, que es combinación de legalidad, de efectividad y de legitimidad. En última instancia, todo se reduce a un volo inicial, a la acción de un primer motor invisible que pone en marcha la máquina sin preocuparse, de ningún otro modo, de su trayectoria ulterior. Concentrada en el vértice de la pirámide normativa, la juridicidad se oculta tras la ficción de la autoridad imaginaria que, se supone, quiere la norma fundamental.

Dejemos, por ahora, estos análisis fundamentales y volvamos, aún un instante, a los trabajos cotidianos de Hércules. Nos queda mostrar cómo su gestión sustituye todos los atributos del dossier por aquéllos que hasta ahora habíamos asociado al modelo el código. El código, decíamos, implica el monismo normativo. El dossier, en cambio, acarrea la proliferación de las decisiones particulares. La generalidad y la abstracción de la ley dejan lugar a la singularidad y a lo concreto del juicio. Del mismo modo, si se considera el fenómeno jurídico por el lado de las prerrogativas individuales, se verá que la categoría del interés, difuso y proteico, tiende a auxiliar a las fronteras simples y a la estricta jerarquía de los derechos subjetivos que había instaurado el Código civil de $1804^{17}$. A la movilidad de los intereses en conflicto responde la flexibilidad de la norma concebida como instrumento variable de medida, compromiso precario, medio estadístico.

Del mismo modo, hay que notar que si el código supone el monismo político, el dossier, en cambio, ocasiona no ya el pluralismo (que supone un principio de articulación), sino la dispersión de las autoridades encargadas de aplicar el Derecho: de cualquier modo, dispersión sin sentido.

El tercer corolario del código era una racionalidad deductiva y lineal, resultando de ello que la vocación del Derecho es ser aplicado al hecho. Pero, desde que es privado de la regla, es recusado; la marcha se invierte y se pretende inductiva. Es del hecho del que surge la regla o, más concretamente, la decisión particular en la que se agota la juridicidad. A decir verdad, la pretensión de coherencia lógica se somete más a menudo a la búsqueda del resultado práctico (la apuesta de la intervención de Hércules era, sobre todo, proponer la regulación más judicial de los intereses rivales) que a asegurar la aplicación

${ }^{17}$ Sobre esta cuestión, cf. F. Ost, Entre droit et non-droit, l'intérêt. Essai sur les fonctions qu'exerce l'intérêt en droit civil, vol. II, de Droit et intérêt, bajo la dirección de Ph. Gérard, F. Ost y M. van de Kerchove, Bruselas, 1990. 
más correcta de la ley. No es la lógica la que servirá de auxiliar al jurista, sino la economía, la contabilidad, la balística, la medicina y la psiquiatría.

Por último, habíamos asociado a la codificación una temporalidad voluntarista y continuista marcada por la pretensión de dominar el futuro de la ley, de asegurar el progreso del orden normativo. El dossier, en cambio, implica un tiempo discontinuo, hecho de irrupciones jurídicas esporádicas y desechables después del uso.

Quizá se puede observar que, con todo, Hércules y Júpiter no son más que dos imágenes del Derecho, dos modelos, dos tipos ideales bastante alejados de la realidad jurídica. Sin duda. Se admitirá, sin embargo, que ellos representan, uno y otro, dos figuras típicas de la imaginería jurídica y es sabido que sería un grave error subestimar la eficacia de este tipo de representaciones.

Sin embargo, advertidos del carácter restrictivo de estas teorías extremas, algunas de ellas intentarán siempre moderar, relativizar, combinar sus tesis respectivas. La mayoría de las teorías generales del Derecho (esas que sostienen en particular los manuales de las facultades) participan de este propósito. Se concebirá, por ejemplo, un legislador a la escucha de lo social, receloso de integrar las sugerencias de una doctrina atenta y de una jurisprudencia razonablemente creadora, capaz de modificar su texto en cada ocasión para ajustarlo a las necesidades del momento. En efecto, no está prohibido pensar que desde lo alto de su Olimpo Júpiter, dialogando con su pueblo, le propone cualquier nueva alianza.

Si Júpiter se humaniza, Hércules podría también, a la inversa, alejarse -al menos parcialmente- de su humana condición y elevarse a cualquier forma de racionalidad superior. Es exactamente por esta vía por la que camina el Hércules de Dworkin, este juez racional que «toma los derechos fundamentales en serio», que domina el «imperio del Derecho», que se consagra en toda ocasión, y particularmente en los «casos difíciles», a encontrar la «respuesta correcta» que se impone. Su religión, en efecto, es la unidad del Derecho, que él debe fortalecer en cada uno de sus juicios: unidad en el doble sentido de la coherencia narrativa que mejor se adapta al estado pasado y presente del Derecho, y de la jerarquía más satisfactoria de los principios de moral política compartidos por la comunidad en cada momento de su historia. Se está entonces muy lejos del decisionismo y del pragmatismo.

¿Hay un desprendimiento por lo tanto de los modelos clásicos? Puede dudarse. ¿No se apunta siempre a reconstruir la unidad ideal del Derecho en un foco único y supremo, garante de toda racionalidad? El juez jupiterino razonaría postulando la racionalidad del legislador; el Hércules de Dworkin postula la unidad del Derecho, 
de la cual se hace a sí mismo paladín. ¿Es ésta realmente una diferencia?

¿No es tiempo de pensar la complejidad del Derecho a partir de ella misma, y no como enmienda y complicación de los modelos simples? ¿No es tiempo de pensar el Derecho como circulación incesante de sentido, más que como discurso de la verdad? ¿No es tiempo de advertir la pluralidad y la diversidad de los actores que juegan sobre la escena jurídica y contribuyen, cada uno a su manera, a «aplicar el Derecho»?

Al monismo habría que oponer, no la dispersión, sino el pluralismo; el absolutismo binario (permiso/prohibición, válido/no-válido) habría que sustituirlo por el relativismo y el gradualismo, que no se transmuta por tanto en escepticismo ${ }^{18}$; a la linealidad jerárquica habría que oponer no la circularidad viciosa, sino la recursividad fecunda; la clausura y el determinismo del discurso habría que sustituirlos por la inventiva controlada de un discurso jurídico radicalmente hermenéutico.

Es en la teoría de un Derecho múltiple en la que habría que fijarse; multiplicidad que no significa, sin embargo, anomia y anarquía. Habría que llegar a mostrar cómo el orden jurídico se nutre del desorden periférico, o incluso interno, y reproduce a su vez desorden. Habría que pensar una autonomía que sea al mismo tiempo heteronomía. Habría que añadir aún el entrelazamiento incesante de la fuerza y de la justicia.

En una palabra, es en la teoría del Derecho como circulación del sentido en la que hay que centrarse. Un sentido sobre el cual nadie, ni el juez ni el legislador, tiene el privilegio. «Privilegio», no se sabría decir mejor, en efecto: «ley privada». La circulación del sentido jurídico opera en el espacio público y nadie podría, sin violencia o ilusión, pretender acapararlo. Hay Derecho antes de los juristas y lo habrá todavía después de ellos. De la inagotable «idea de Derecho» o aspiración a la justicia, sin duda ellos son hoy los intérpretes más autorizados, pero esta consagración no les asegura, sin embargo, ningún monopolio.

Hay pues, en el sentido fuerte del término, «juego» del Derecho. Este sentido fuerte es un sentido neutro o medio: como se

${ }^{18}$ En este sentido, cf. A-J. Arnaud, «Repenser un droit pour l'époque postmoderne», en Le courrier du CNRS. Les sciences du droit, abril 1990, pág. 81: «Filósofos, teóricos y sociólogos se esfuerzan actualmente por sustituir el Derecho rígido, fundado sobre la todopoderosa ley, por un Derecho flexible que toma en cuenta el relativismo, el pluralismo y el pragmatismo característicos de la época postmoderna». 
habla del «juego» de las olas o del «juego» de las luces; hay una especie de movimiento endógeno del Derecho, de producción interna, no como deseo de no se sabe qué orden jurídico hipostático, sino como proceso colectivo, ininterrumpido y multidireccional de circulación del logos jurídico ${ }^{19}$.

Es a Hermes, dios de la comunicación y de la circulación, dios de la intermediación, personaje modesto en el oficio de representante y portavoz que es olvidado en beneficio de la prosecución del juego mismo, a quien confiamos la tarea de simbolizar esta teoría lúdica del Derecho.

\section{Hermes, la red y el banco de datos}

La imagen de la red se impone hoy en un buen número de campos. El peligro al que se expone el análisis de este paradigma nuevo y complejo es el de caer en el esoterismo. Se ha evocado, por ejemplo, la estructura en $\left\langle\text { rizoma» }{ }^{20} \text {, la } \text { «heterarquía }\right\rangle^{21}$, o incluso las «anastomosis» del Derecho ${ }^{22}$. El riesgo es grande desde el momento en que se descubre la imposibilidad de monopolizar la interpretación, de renunciar a toda interpretación y de contentarse con registrar una multitud de miniracionalidades en el seno de una racionalidad global incontrolable a partir de ahora. Se trata seguramente de uno de los riesgos de la cultura postmoderna ${ }^{23}$. El problema consiste, una vez más, en abandonar la monofonía por la polifonía sin caer necesariamente en la cacofonía -el «ruido», como se dice en lenguaje informático, lo carente de significado-.

Sin embargo, la peculiaridad de la red jurídica no es tal que sea imposible escaparse de las líneas de fuerza. Sólo es necesario aprender a identificar cuidadosamente todos los nudos, a reparar los flujos de informaciones, a mostrar las interacciones de las funciones. Se verá entonces que el sentido producido dentro de la red no es totalmente

${ }^{19}$ Sobre este sentido medio del juego, cf. II. G. Gadamer, Vérité et méthode, trad. por E. Sacré, París, 1968, pág. 30.

${ }^{20}$ G. Delcuze y F. Guattari, Mille plateaux. Capitalisme et schizophrénie, París, 1980, pág. 32: «Sistema sin centro, no jerárquico y no insignificante, sin dirección y sin memoria organizadora o autómata central, únicamente definido por una circulación de estados».

${ }^{21}$ D. Hofstadter, Gödel, Escher, Bach. Les brinds d'une guirlande éternelle, París, 1985: programa desprovisto de monitores y consistente exclusivamente en redes de transiciones entremezcladas.

${ }^{22}$ J.-L. Vullierme, «Les anastomoses du droit. Spéculations sur les sources du droit», en Archives de philosophie du droit, París, Sirey, t. 27, pág. 11.

${ }^{23}$ En este sentido, cf. B. de Sousa Santos, «La Transition postmodeme: droit et politique», en Revue interdisciplinaire d'études juridiques, 1990, 24, pág. 32. 
imprevisible, porque siempre hay textos a interpretar; se verá igualmente que las relaciones de fuerza que ahí se desarrollan no son totalmente aleatorias, porque también permanecen jerarquías, especialmente institucionales. Esta interpretación puede ser inventiva, del mismo modo que estas jerarquías pueden ser enmarañadas ${ }^{24}$.

Esta situación combinatoria -se podría decir, en un lenguaje más antropológico, «intersubjetiva»- reenvía a la ontología del Derecho, a eso que Paul Amselek llamaba recientemente «la peculiaridad ontológica del Derecho» ${ }^{25}$. Signo lingüístico, el Derecho pide en efecto ser interpretado por sus destinatarios; manifestación de voluntad, el Derecho pide ser interiorizado y aceptado. A partir del momento en que los «sujetos de Derecho» -que no son sujetos del Derecho, sino mejor sujetos de Derecho, es decir, todo a la vez, seres susceptibles de derechos y coautores del Derecho- reconstruyen mentalmente el mensaje que se les dirige y mediatizan su puesta en práctica con una operación de voluntad (que es también una manifestación de libertad), el Derecho se configura como algo necesariamente inacabado, siempre en suspenso y siempre relanzado, indefinidamente retomado en la mediación del cambio.

Esta aproximación ontológica podría, a su vez, ser desarrollada y perseguida bajo el plano de la descripción de las formas inéditas que toman los sistemas jurídicos postmodernos.

Si es verdad que somos al mismo tiempo los herederos del Derecho liberal generado por el Estado de Derecho y del Derecho social producido por el Estado asistencial, si es verdad también que estas dos formas de Estado han entrado ellas mismas en crisis, sin por ello haber desaparecido, si es verdad, en fin, que de estos trastornos surge un Derecho postmoderno cuyos contornos no se delinean nítidamente, se comprobará entonces el grado de complejidad de la situación presente.

Primer indicio: la multiplicidad de los actores jurídicos. Se habla mucho, y con razón, del juez. Pero no habría que minimizar la intervención del legislador quien, más que nunca, «se despliega en normas». Incluso la técnica tradicional de la codificación, que se creía abandonada, está de nuevo de moda. ¿Hay que acordarse en este punto de que Francia ha empezado con mucha determinación, parece, la reforma de su Código penal? En la circular «Rocard» del

${ }^{24}$ Sobre este punto, J. F. Ost y M. van de Kerchove, «Creation et application du droit. Structure circulaire du système juridique?», en Jalons pour une théorie critique du droit, Bruselas, 1987, págs. 183-253.

${ }^{25} \mathrm{P}$. Amselek, «L'Etrangeté ontologique du dron», en Droits. Revue française de théorie $d u$ droit, 1990, págs. 88-92. 
25 de mayo de 1988, de cara a la formulación de un «código de deontología de la acción gubernamental», se ha dicho que «la codificación ofrece un marco privilegiado para reunir un cuerpo de reglas hasta entonces disperso, modernizando y simplificando el Derecho». En cuanto a la administración, nadie discutirá que ella se ha atribuido (en favor del intervencionismo sistemático concomitante a la aparición del Estado asistencial, que se ha hecho paulatinamente compensador, redistribuidor, pedagogo, terapeuta, industrial y banquero) un lugar preponderante -algunos pensarán: el primero- en el proceso de producción normativa ${ }^{26}$. ¿Habría que estudiar igualmente el rol de los particulares, de las asociaciones y de las sociedades comerciales en la circulación de las normas jurídicas? Sería una grave confusión limitar su intervención al campo de las relaciones privadas. Puesto que el Derecho es concebido a partir de ahora al menos tanto como un sistema de recursos que como un conjunto de mandatos, aparece el papel esencial de «usuarios» del Derecho en la movilización de estos potenciales jurídicos. La suerte de muchas políticas públicas dependerá así de las iniciativas privadas tomadas por los usuarios, en el sentido de la ampliación de las normas jurídicas que las traducen o, al contrario, de la resistencia a ellas ${ }^{27}$.

Esto conduce a formular un segundo indicio de los cambios actualmente observables: se trata de la imbricación sistemática de las funciones desde el momento en que las agrupaciones (como por ejemplo los sindicatos) son asociadas, con títulos diversos, a las responsabilidades del poder público; desde que la justicia presta a la administración sus procedimientos y su estilo; desde que esta última participa en la elaboración de las normas generales, mientras que la legislación parlamentaria no se distingue bien, en la mayor parte de los casos, de las disposiciones reglamentarias; desde que la función jurisdiccional se difunde en el conjunto de los otros poderes, públicos y privados (piénsese en las comisiones de encuesta parlamentaria, en las múltiples jurisdicciones administrativas, en los diversos comités de ética...).

Tercer indicio de complejidad: la multiplicación de los niveles de poder. A la división binaria que separa, en el marco del Estado liberal, el Estado y la sociedad civil, le ha sustituido una estratificación muy densa de poderes. El Estado debe negociar con las instancias

${ }^{26}$ En este sentido, cf. C.-A. Morand, «Le Droit de l'Etat providence», en Revue de droit suisse, Bâle, 1988, pág. 534: «Por razón de los problemas que debe resolver el Estado asistencial y de la acción en red que desarrolla, la administración es el centro de la producción y de la puesta en práctica de las normas»».

${ }^{27}$ Sobre este punto, cf. P. Lascoumes, «Normes juridiques et mise en oeuvre des politiques publiques», en L'année sociologique, 1990, 40, págs. 50 y ss. 
regionales y locales desde el momento mismo en que concede importantes transferencias de soberanía a los órdenes jurídicos supra-nacionales europeos. Del mismo modo, no es raro que se introduzcan formas de autorregulación de las cuales se sirven los poderosos operadores económicos transnacionales; estos códigos de buena conducta emanan de compañías petroleras para asegurar (y también para limitar) la indemnización de las catástrofes ecológicas de las que sean responsables. El Derecho de las Comunidades Europeas representa, en este punto, una nueva nebulosa en el firmamento de los fenómenos jurídicos. Por ejemplo, existen 20.000 directivas y reglamentos en vigor y, por eso, este Derecho constituye a la vez el resultado de un proceso de racionalización y de normalización que no está exento de un nuevo tipo de riesgo de burocratización: el «eurócrata»; sin embargo, se suscita un entusiasmo sin precedentes, como si la Europa, nuevo mito político, recondujera hoy a la figura del «legislador supremo», ese déspota ilustrado, ideal de las Luces, para escapar del cual tenemos decididamente problemas ${ }^{28}$.

Finalmente, estos diversos cambios no dejan de ocasionar sustanciales modificaciones de las modalidades de acción jurídica. Si el Estado liberal podía satisfacerse sólo con las modalidades de permitido, prohibido y obligatorio (en aplicación de las reglas de bronce: para los particulares, «todo lo que no está prohibido está permitido» y para el poder público, «todo lo que no está explícitamente autorizado está prohibido»), en cambio, el Estado presente experimenta una gama casi infinita de intervenciones sobre las cosas y las conductas. Desde el momento en que pretende conducir el cambio social y no sólo enmarcar el mercado, el Estado promete, incita, planifica (o, a la inversa, disuade de llevar a cabo las conductas que considera no deseables). Para este fin pondrá en práctica una vasta panoplia de instrumentos flexibles para la dirección de la acción social: planes, recomendaciones, presupuestos, declaraciones gubernamentales, pactos políticos, circulares administrativas para asuntos externos, concertación y contractualización... Técnicas que se inscriben en secuencias complejas de acción que miran a la realización de programas finales, al servicio de los cuales estas modalidades (jurídicas y para-jurídicas) se otorgan un mutuo apoyo. De este modo es bien conocido que la concertación se realiza bajo la amenaza de la adopción de una legislación de autoridad, igual que en Derecho penal la transacción aparece como sustituta de una sanción

${ }^{28}$ «Cf. B. Oppetit, «L'eurocratie ou le mythe du législateaur suprême», en Dalloz, 1990, Chron., XIII, págs. 73-76. 
más fuerte, mientras que, a la inversa, las leyes votadas por el Parlamento dejan generalmente a la administración un confortable margen de maniobra para permitirle prevenirse contra toda eventualidad. Y si, casualmente, se considera que la intervención directa se revela ineficaz, el Estado se hará «reflexivo», como se dice en la teoría general del Derecho alemán: se contentará con instalar un marco procedimental para canalizar la autonomía de los subsistemas suficientemente diferenciados, y capaces de autorregularse ${ }^{29}$. Todas las estrategias, tanto simbólicas como instrumentales, parecen desde entonces ser utilizadas simultáneamente. Se desreglamenta, pero a menudo esto no es más que una manera de reglamentar de otro modo ${ }^{30}$; se despenaliza, pero con frecuencia es en provecho del redesarrollo de otras medidas coercitivas, tales como la medicalización o la fiscalización para los comportamientos indeseables ${ }^{31}$; se desjudicializa, pero es para colocar inmediatamente mecanismos de peritaje, de conciliación, de mediación o de arbitraje ${ }^{32}$.

¿Quién se extrañará de que, en esas condiciones, el Derecho sea a la vez estable y efímero o experimental, duro y blando (hard y soft), coyuntural y principial (jamás se ha hablado tanto como hoy de los principios generales del Derecho, gracias especialmente al trabajo creativo de las altas jurisdicciones nacionales y europeas)? ¿Quién no se percata de que el Derecho proviene a la vez del centro del orden normativo mismo y de la periferia, del desorden (o de órdenes distintos) que prevé en el exterior? ¿Quién no se percata de que las fronteras entre interior y exterior se han convertido en porosas, incluso en reversibles, como si la juridicidad adoptara hoy el recorrido paradójico de la banda de Möbius que la dirige vuelta a vuelta, y sin transición, del centro a la periferia y del exterior al

${ }^{29}$ Cf. G. Teubner, «Reflexives Recht», en ARSP, LXVIII, 1982, págs. 13 y ss.; H. Willke, Systemtheorie entwickelter Gesellschaften, Weinheim, 1989.

${ }^{30}$ En este sentido, cf. Chevallier, «Les enjeux de la dérèglementation», en Revue du droit public et de la science politique en France et à l'étranger, vol. 103, n. ${ }^{\circ} 2,1987$, pág. $286 \mathrm{y}$ ss.

${ }^{31}$ En este sentido, M. van de Kerchove, «Les différentes formes de baisse de la pression juridique et leurs principaux enjeux», en Cahiers de recherche sociologique, n. ${ }^{\circ} 13$, otoño 1989, págs. 11 y ss.

${ }^{32}$ Como bien muestra J. Commaille, una observación atenta del Derecho en vigor en las sociedades modernas complejas revela un flujo y reflujo alternativo de la regulación jurídica y de la regulación social, consideradas como las dos caras de una misma moneda. Todo movimiento de regulación o desregulación jurídica es entonces extensamente ambivalente; intenta, a partir de ahora, inscribirse en una regulación social más global («Familles, interventions et politiques. Nouvelles régulations sociales?», en n. ${ }^{\circ}$ especial de los Annales de Vaucresson, Vaucresson (CRIV), 27-1987/2, págs. $101 \mathrm{y}$ ss. 
interior? No es suficiente hablar de Derecho «flexible», como lo hacía no hace mucho Jean Carbonier; o incluso de Derecho «blando», como se dice hoy. Es a un Derecho «líquido», intersticial e informal al que estamos confrontados ahora. Un Derecho que, sin cesar de ser él mismo, se presenta en ciertas ocasiones en el estado fluido que le permite colocarse en las situaciones más diversas y ocupar así suavemente todo el espacio disponible, soportando -llegado el caso- fuertes compresiones. El Derecho, asociado a la idea de rigidez -el Derecho, regla de acero- ¿podría entonces ser líquido? Se conocía ya, tolerada en los márgenes del sistema, la equidad, comparada a menudo con la regla de plomo, metal flexible, utilizado en Lesbos en la construcción para amoldarse a las sinuosidades de la piedra. ¿Pero una regla líquida? ¿Y por qué no, si incluso ciertos metales como el mercurio presentan esta particularidad ${ }^{33}$ ¿Es realmente una casualidad que los alquimistas de la edad media dieran el nombre de «mercurio», equivalente latino del Hermes griego, a un metal tan particular?

Aunque todavía muy incompleto, este cuadro ya es algo complejo. ¿No presenta el riesgo de desorientar al observador en los circuitos de la red, o de asfixiarlo bajo la proliferación de las informaciones? ¿Cuál es, pues, el hilo de Ariadna de este laberinto, el código de este banco de datos? No se encontrará en ninguna causalidad exterior (como la infraestructura económica en la vulgata marxista), ni en un mecanismo de mando central. Sólo la ley misma de circulación del discurso jurídico puede aclarar su génesis y su desarrollo. Es aquí donde nos encontramos con Hermes y la teoría lúdica que él simboliza.

Antes de ser regla e institución, el Derecho es logos, discurso, significado en suspenso. Se articula entre las cosas: entre la regla (que no es nunca enteramente normativa) y el hecho (que no es nunca enteramente fáctico), entre el orden y el desorden, entre la letra y el espíritu, entre la fuerza y la justicia. Dialéctico, es el uno por el otro; paradójico, es el uno y el otro. Sólo una teoría lúdica del Derecho está en condiciones, en nuestra opinión, de dar cuenta de las vueltas y rodeos de tal racionalidad paradójica.

Retengamos, por ahora, cinco rasgos de esta idea de juego.

En primer lugar recordaremos que el juego tiene en sí mismo su propio movimiento; como una figura de danza o un efecto de estilo, dibuja su propio espacio en cuyo seno se despliega su creatividad endógena. Es el sentido neutro o medio del juego el que hace que no entre impunemente en el círculo mágico que traza; se asumen

${ }^{33}$ En este sentido, cf. P. Amselek, op. cit., pág. 89. 
roles al menos parcialmente determinados, como en la comedia o en la estrategia, se adoptan estilos discursivos, se utilizan argumentaciones, se respetan los topoi (lugares comunes) y las autoridades que los imponen. Se dirá, en el lenguaje de Bourdieu, que el juego del Derecho baliza un campo generador de hábitos.

Segundo rasgo, que matiza lo que el primero podría sugerir de determinismo: el juego, y particularmente este inmenso juego de sociedad que es el Derecho, acepta un número indefinido de jugadores cuyos roles y réplicas no están enteramente programados. De una parte, pueden entrar en juego jerarquías enredadas en extraños bucles; como hemos visto, delante del escenario se ponen a veces roles secundarios. Por otra parte, cada participante en el juego del Derecho es simultáneamente introducido en otros partidos que se celebran sobre otros campos: particularmente familiares, económicos y políticos. Inevitablemente, se establecen interferencias entre estos diversos juegos sociales que son también juegos del lenguaje. De aquí resulta una transformación permanente, a veces lenta, a veces rápida, no sólo de las «jugadas» autorizadas por las reglas en vigor, sino igualmente de estas mismas reglas. Se comprende ahora el lazo que une este segundo rasgo con el primero: si el juego está abierto a todos (o al menos a la mayoría, la observación merecería, por supuesto, ser matizada), no está reservado exclusivamente a nadie. Ningún jugador, sea cual sea su posición de fuerza y/o autoridad, puede pretender decir la primera y la última palabra. Sin un mínimo de azar, de apertura y de incertidumbre no hay ya juego, ni historia, ni Derecho, sólo violencia pura o beatitud eterna.

El tercer rasgo, sin duda el más importante, insiste sobre la naturaleza mixta del juego que combina, en proporción variable, la regla y el azar, la convención y la invención, la apertura y el cierre. La lengua inglesa expresa bien esta dualidad, en cuanto dispone de dos términos para decir «juego»: play que apunta sobre todo al juego libre e improvisado, y game que reenvía al juego reglamentado. Pero bien se trate de la liberación más desenfrenada -como la inversión carnavalesca de las tradiciones- o bien del juego sometido a las convenciones más estrictas -como una partida de ajedrez-, todo juego comporta una parte de reglas y una parte de improvisación. De este modo, la práctica del juego no se reduce ni al respeto de las reglas, ni a la indeterminación pura y simple. Más allá de las reglas no está el vacío, sino un «espacio de juego» que evalúa y explota el «sentido del juego» como intuición práctica del sentido producido por el juego mismo. El elemento central de este «sentido» o «espíritu del juego» es sin duda la adhesión a las «metas del juego» y a sus «apuestas» más fundamentales. Este modelo muestra una gran fecundidad para presentar las operaciones de interpretación y de 
validación a las cuales se dedican cotidianamente los juristas. Si Júpiter insiste en el polo «convención» y Hércules en el polo «invención», Hermes, en cambio, respeta el carácter hermenéutico o «reflectante» del juicio jurídico que no se reduce ni a la improvisación ni a la simple determinación de una regla superior.

Mencionaremos todavía, para no olvidarlos, otros dos rasgos de la idea de juego, aunque sin desarrollarnos aquí ${ }^{34}$. Se dirá, de una parte, que la idea de juego permite articular la distinción y concebir las relaciones entre un polo simbólico, el del juego como representación, y un polo utilitarista, el del juego como estrategia. Estas lógicas, tan pronto distintas, incluso opuestas, como luego combinadas, caracterizan con certeza a los juegos sociales y encuentran, en el campo jurídico, innumerables ilustraciones. Por fin, se revelará el último rasgo inherente al concepto de juego, que es situar la distinción del interior y del exterior, el límite del juego y del «fuera de juego», la frontera que separa el sistema y su medio ambiente. Pero, como se ha visto, tales fronteras no dejan de ser móviles y paradójicas: todo esto transcurre como si los límites del Derecho y del no-Derecho fueran reversibles. Todo esto transcurre como si las fronteras del sistema jurídico fueran tanto externas como internas: aparece Derecho en el corazón del no-Derecho, mientras que se desarrolla no-Derecho en lo más profundo del Derecho. Un juego, como el Derecho, es siempre, al mismo tiempo, algo más que él mismo, a pesar de los esfuerzos desarrollados por uniformizar su funcionamiento y homogeneizar sus datos. En él todavía subsiste, a veces en el estado de simples potencialidades, el «no-juego», el «otro juego» o el «doble juego».

He aquí entonces, muy sucintamente evocadas, algunas líneas de fuerza de una teoría del juego que podrían servir de base a una teoría general del Derecho adecuada al Derecho en red o al Derecho de Hermes. Nos queda, sin embargo, abordar una última cuestión que no nos es permitido eludir. Se trata de la cuestión ética. En efecto, quizá se piense que el modelo del juego, que evoca algo de la burla y del frívolo postmoderno, ha despejado, desde hace muchísimo tiempo, la preocupación por la legitimidad, guardada (como muchos otros discursos «modernos») en el armario de los recuerdos históricos. Y nuestros atentos oyentes se acordarán quizá de que en el panteón antiguo, Hermes, mensajero de los dioses $\mathrm{y}$

${ }^{34}$ Para más detalles, cf. F. Ost y M. van de Kerchove, «Les rôles du judiciaire et le jeu du droit», en Acteur social et délinquance. Une grille de lecture du systeme de justice pénale. En hommage au professeur Christian Debuyst, Lieja-Bruselas, 1990, págs. 271-293. 
dios de los mercaderes, es igualmente el dios de los ladrones. ¿Conducirá entonces el cambio necesariamente a la explotación, la discusión pública a la demagogia, la interpretación o la traducción a la traición? ¿Cómo entonces, si se rechaza esta conclusión que significaría el fin del Derecho, moralizar a Hermes sin desnaturalizarlo? Dicho de otro modo: ¿Qué legitimidad concebir para un Derecho postmoderno incompatible con todo discurso de autoridad?

Para tratar de reflejar esta dudosa cuestión, querríamos sugerir una serie de observaciones finales. Las dos primeras pretenden insistir sobre logros a los cuales parecería difícil renunciar. Estos puntos deberían ser recordados desde el momento en que despunta el doble riesgo del fanatismo nacionalista y del integrismo religioso, como si la complejidad postmoderna, decididamente demasiado fluida para creer en ella, engendrara esos violentos brotes regresivos.

El primero de estos logros concierne a la legitimidad procedimental del Derecho. Sea cual fuere el contenido material de las soluciones que impone, el Derecho es ante todo un procedimiento de discusión pública razonable, un modo de solución de conflictos equitativo y contradictorio. Desde que nuestras sociedades se representan como autoconstituyentes y ya no buscan en alguna garantía meta-social el modelo a seguir, desde el momento en que nuestras reglas, incluso las más fundamentales, se muestran convencionales, la primera garantía de legitimidad reside en el respeto a las condiciones de la discusión sin coacción. Este respeto a las formas, a los plazos, a los procedimientos es realmente esencial y consubstancial al Derecho. Tiene el doble mérito de descalificar a la vez a la violencia que intentaría imponer su punto de vista por la fuerza y a la buena conciencia mayoritaria que arriesga todo por imponer sus opiniones en nombre del pretendido consenso. El procedimiento jurídico, parlamentario y judicial, traza (en sentido propio y también figurado) el espacio de la controversia; ella asegura la puesta en escena o la formulación de la contestación, de la disidencia, de la defensa. Vuelve visible la división social y propone las vías argumentativas para hacerla negociable. Tal es, seguramente, el mérito esencial y la radical originalidad de la democracia. Tal es también la virtud de la intervención del juez en el conflicto. Más que el mérito intrínseco de la decisión que sería llevado a tomar, es la interposición que opera en el corazón de una relación de fuerza lo que constituye su legitimidad. Es la triangulación misma la que es legítima: esta digresión, por mínima que sea, esta ligera separación que se impone entre una voluntad y su realización. Esta mediación, tan débil y formal como aparece, constriñe a las partes en el proceso a «decir» su situación, a verbalizar su pretensión, a justificar en el lenguaje común y también en forma jurídica su comportamiento y 
su «buen derecho». Haciendo esto, están ahí, frente a frente, constreñidas a tomar los caminos de la discusión racional. Hermes ha desempeñado su oficio que, mediatizando las pasiones, les libra de la violencia pura y simple. La Comisión y la Corte Europea de Derechos del Hombre no se equivocan al privilegiar sistemáticamente, de entre todos los derechos fundamentales del Tratado de los cuales tienen la custodia, el sexto, que se ocupa precisamente de las garantías del proceso equitativo. «Jurisdiccionalizando» también los conflictos periféricos, tales como los disciplinarios y administrativos, los órganos de la Convención de Derechos del Hombre aseguran, al mismo tiempo, la penetración de los derechos fundamentales en los espacios cada vez más amplios de la sociedad. Esta consideración asegurará la transición a nuestra segunda observación.

Algunos, en efecto, sostienen hoy con entusiasmo que esta mediación procedimental constituye toda la legitimidad del Derecho que, por lo demás, puede presentar no importa qué contenido. Tal es, posiblemente, la debilidad intrínseca del liberalismo político auténtico: al profesar tolerancia hacia todas las opiniones por igual, no puede garantizar absolutamente ninguna, ni siquiera la suya propia; sabemos que algunas de nuestras democracias occidentales han tenido, a lo largo de siglo XIX, la experiencia dolorosa de este tipo de liberalismo. La Convención Europea de los Derechos del Hombre ha aprendido la lección recordando, en su artículo 17, que no ha de haber libertad para los enemigos de la libertad -la Corte vela, en lo que le concierne, por aquél que no haya abusado de este artículo-. Nuestra segunda observación tiende entonces a mostrar el lazo necesario que se establece entre el respeto a los procedimientos y los derechos fundamentales. Si se dirige, en efecto, a favorecer a la minoría, así como a dar sistemáticamente la palabra a la defensa, está bien que se reconozca a cada uno el derecho de expresión, incluyendo al más débil y al más extraño. Al encuentro de la dialéctica identidad («nosotros»)/exclusión («ellos»), los procedimientos jurídicos tienen este efecto de universalizar y, por lo tanto, de igualar, al menos parcial o potencialmente, el derecho a la palabra. Al mismo tiempo, estos son los principales derechos que son reconocidos: libertad de opinión y de expresión, integridad física y seguridad (no podría haber debate equitativo bajo apremio de la coerción física). Las diferentes formas que toman estas libertades de opinión y de expresión -libertad de sufragio político, derecho de asociarse y de sindicarse, libertad de prensa y de enseñanza...- serán cuestión de inventiva de las comunidades políticas, al igual que los nuevos derechos que serán reivindicados en la dinámica misma del derecho a la palabra, del derecho «a tener derechos» que ha sido reconocido. No es entonces exacto sostener que el Derecho y 
la democracia conducen a una regla de juego puramente formal, compatible con no importa qué contenido material. Esta regla del juego implica, al contrario, el respeto al jugador y le garantiza, si no un handicap que le iguala con los participantes más experimentados o más poderosos, al menos el derecho a hacer valer su punto de vista.

Estas dos primeras observaciones se dirigen a preservar, en el modelo de Hermes, los logros de la cuestión de la legitimidad tal y como el pensamiento y la lucha de las generaciones que nos han precedido los han configurado. Las dos observaciones que siguen insistirán sobre nuevas cuestiones que estaría bien tomar en cuenta en protección de las generaciones que nos sucederán: ¿Hermes, encargado de la comunicación entre los vivos y los muertos, no podría igualmente, en una civilización seguramente volcada más hacia el futuro que hacia el pasado, preocuparse de los futuros huéspedes del planeta?

El primer punto se dirige a acreditar la idea de que el hombre no es solamente sujeto de Derecho, sino igualmente titular de responsabilidades. Al encuentro de una cierta retórica de los derechos del hombre, que, en ciertos casos, desvían esta categoría prestigiosa para cubrir las reivindicaciones inmediatas de los deseos más individualistas, hay que recordar que una comunidad descansa igualmente sobre las responsabilidades asumidas colectivamente. Esta idea, muy atacada desde la revolución de 1789, sólo se manifestará muy progresivamente. La primera generación de derechos, la de las «libertades-inmunidades», aparece como el escudo que protege al individuo contra las usurpaciones del poder público. En este caso todos los derechos están del lado de la persona, todos los deberes del lado del Estado. La segunda generación de derechos, la de los «derechos económicos y sociales», tiende a asegurar un igualación de las condiciones materiales y espirituales de existencia. Una cierta solidaridad se manifiesta aquí, pero sólo bajo la forma de retenciones fiscales y parafiscales destinadas a subsidiar los servicios públicos encargados de asegurar el buen fin de estas prestaciones, aunque esta solidaridad pasa a un segundo plano detrás de la reivindicación misma, de modo que no se sale, por tanto, del solipsismo. En cambio, la tercera generación de derechos -categoría que, a decir verdad, está todavía en los limbos jurídicos- se ocupa de dar contenido a la idea de solidaridad o, por seguir la progresión marcada por la divisa revolucionaria francesa, a la idea de fraternidad, que sucedería así a la libertad, característica de las «libertades-inmunidades», y a la igualdad, característica de los «derechos económicos y sociales». Estos derechos de solidaridad, como el derecho al respeto del medio ambiente, el derecho al reparto de los recursos comunes de la humanidad o el derecho a la paz, se analizan 
más como intereses legítimos que como derechos subjetivos y libertades. Puede que, incluso, aquí la idea de obligación prevalezca sobre la del derecho. Se trata seguramente de responsabilidades colectivas más que de prerrogativas individuales. Sin duda, todo derecho subjetivo conlleva un deber correspondiente en la persona de otro; no se negará sin embargo que la imaginería jurídica, como el discurso político, han ocultado por mucho tiempo esta realidad, de modo que la insistencia sobre la idea de responsabilidad - ¿para cuándo una «Declaración de las responsabilidades universales»?- conllevaría un profundo trastorno de las mentalidades.

Esto nos lleva a formular nuestra siguiente observación, que se ocupa esta vez de insistir sobre el cambio de escala al cual el jurista, como los demás contemporáneos, está hoy constreñido. Mientras que en el antiguo régimen sólo se concebía y practicaba la norma a escala familiar y local, el progreso de la modernidad tuvo que adaptarse a la escala nacional, la época actual nos obliga a razonar -realmente y no sólo verbalmente- a escala universal, eso que K. O. Apel califica de «macroesfera» que exige normas intersubjetivamente válidas de responsabilidad universal. Los nuevos peligros de nuestro tiempo, desde el más público, como la nube de Chernobyl, hasta el más íntimo, como el virus mortífero del SIDA, implican una reacción concertada a escala planetaria. Tal regulación no tiene la menor posibilidad de imponerse si no puede tener apoyo sobre una conciencia ética ampliada a las dimensiones de la comunidad universal. Elevar la democracia a la talla de una ciudad mundial, cuidando de la suerte de las generaciones futuras, constituye la apuesta más considerable del Derecho postmoderno.

Podríamos, sin duda, dejarlo ahí; tan vasto es el programa del cual se encarga nuestro Hermes. Sin embargo, le esperan todavía otros retos que se verá obligado a superar. Pensemos esta vez en las cuestiones ético-jurídicas radicalmente nuevas que suscita la acción combinada de los progresos científicos y de los deseos más delirantes: ingeniería genética y manipulaciones biológicas al servicio de la eugenesia, de la reproducción de clónicos, de la determinación del sexo de los hijos y otros comercios genéticos. Tal articulación de realización técnica y de autoridad volitiva muestra claramente déficits de sentido profundamente desestabilizadores. ¿Cuál podría ser aquí el mensaje de Hermes?

Ante todo, un mensaje muy antiguo, tan viejo sin duda como el Derecho mismo. Es la restauración de la vieja regla de prudencia de la que cierto Derecho extrae su nombre: prudentia, jurisprudentia, jurisprudencia. «En la duda, absténte», dice Hermes, el jurista. $\mathrm{Y}$ recordemos que el procedimiento es precisamente la institucionalización de la prudencia, la instauración de una tregua, el tiempo de 
la reflexión. El procedimiento abandona su suerte a la duda. Esta suspensión de los proyectos societarios más soberanos tiene también por vocación dar tiempo a la memoria, esta memoria social que Hannah Arendt ha mostrado que era a veces el único escudo contra los propósitos del totalitarismo.

Pero es probable que esta temporalización y esta abstención prudenciales no sean suficientes. Un día u otro, Hermes será constreñido a decidir. Nadie sabe cómo lo hará. Se puede, sin embargo, desear que él, el virtuoso de los juegos del lenguaje, se acuerde de que cada uno de ellos tiene su especificidad y de que, concretamente, no corresponde al juego del Derecho ir a remolque del juego de la ciencia. Derecho y ciencia constituyen la inaccesible «realidad» según sus propios paradigmas. Si la ciencia tiene sin duda la ventaja de la intervención operativa sobre lo real -es el «reino de la técnica»-, nada en cambio le asegura un privilegio sobre el plano de la «verdad», y todavía menos sobre el plano de la legitimidad, de su discurso. Al contrario, en una sociedad organizada es al Derecho al que corresponde actuar sobre los aspectos más fundamentales. Más incluso que su función sancionadora y, a fortiori, gestionadora, es la función de nominalización, de clasificación y de jerarquización la que constituye la función propia del Derecho. Decir quién tiene qué, quién hace qué y quién es quién, es el rol esencial del Derecho. Sin duda esta palabra instituyente no es destinada a la inmovilidad, ni consagrada a la repetición pura y simple; como todo mensaje de Hermes, interpreta los discursos circundantes y se presta ella misma a la reinterpretación. Pero no por esto debiera abdicar de su autonomía.

Trazar, en algunas páginas y algunas decenas de minutos, un modelo para el Derecho postmoderno era sin duda un proyecto desmesurado, incluso con la ayuda de un guía tan preciado como Hermes. También, en el momento de concluir, querría evocar las palabras tan sabias del decano Vedel que, al término de una larga y fecunda carrera de jurista, decía: «Si no sé apenas qué es el Derecho, sé bien, en cambio, qué sería una sociedad sin Derecho» ${ }^{35}$. La tarea de aplicar el Derecho es entonces una obra hermenéutica, un trabajo siempre recomenzado.

(Trad. Isabel Lifante Vidal)

${ }^{35}$ G. Vedel, «Indéfinissable, mais présent», en Droits, revue française de théorie juridique, n. ${ }^{\circ} 11,1990$, pág. 71 . 